\title{
Community Pharmacists' Views of the Enforced Antibiotics Dispensing Law and Its Impact on Oral Antibiotics Sales in Saudi Arabia
}

This article was published in the following Dove Press journal: Risk Management and Healthcare Policy

\author{
Mohammed AIRukban (iD ${ }^{1, *}$ \\ Yazed AIRuthia $\mathbb{D D}^{2,3, *}$ \\ Majed Almasaoud ${ }^{4}$ \\ Mohammad Al-Owairdhi ${ }^{5}$ \\ Anwar Alsouan (1D ${ }^{4}$ \\ Abdullah Alrabiah ${ }^{4}$ \\ Abdulrahman Alshaikh ${ }^{4}$ \\ Adel Alsuhaibani (iD ${ }^{4}$ \\ Alan Aleidan ${ }^{4}$ \\ 'Department of Family Medicine, College \\ of Medicine, King Saud University, Riyadh, \\ Saudi Arabia; ${ }^{2}$ Department of Clinical \\ Pharmacy, College of Pharmacy, King \\ Saud University, Riyadh, Saudi Arabia; \\ ${ }^{3}$ Pharmacoeconomics Research Unit, \\ College of Pharmacy, King Saud \\ University, Riyadh, Saudi Arabia; ${ }^{4}$ College \\ of Medicine, King Saud University, Riyadh, \\ Saudi Arabia; ${ }^{5}$ Department of \\ Pharmacoeconomics and Drug Pricing, \\ Saudi Food and Drug Authority, Riyadh, \\ Saudi Arabia
}

*These authors contributed equally to this work

\begin{abstract}
Objective(s): The aim of this study was to explore community pharmacists' views toward the antibiotics dispensing law that was enforced in May 2018 and bans the sale of antibiotics without a prescription in community pharmacy settings in Saudi Arabia. Moreover, the potential impact of the law enforcement on the sales of oral antibiotics in Saudi Arabia was also explored.
\end{abstract}

Methods: A questionnaire-based cross-sectional study was conducted between September 2019 and March 2020 in Riyadh, Saudi Arabia. A multistage sampling technique was used to recruit community pharmacists from different districts. Pharmacists who consented to participate and reported practicing prior to the law enforcement were interviewed about their views of the law using a 14-item newly developed questionnaire. The annual sales of oral antibiotics for the years of 2017, 2018, and 2019 were retrieved from the Saudi Food and Drug Authority (SFDA) database.

Results: Two hundred and eighty six pharmacists consented to participate and met the inclusion criteria. After the law enforcement, approximately $51 \%$ of the participants reported that the percentage of patients seeking antibiotics without a prescription is less than $25 \%$. Moreover, the majority $(87.41 \%)$ reported a drop in the sales of antibiotics. Additionally, about $90 \%$ of the participants believed that the rate of inappropriate use of antibiotics will decrease as a result of the law enforcement. About $41 \%$ of the participants reported that the law has negatively impacted their pharmacies' profits. The sales of oral antibiotics have seen a $16.6 \%$ drop in the year of 2019 as compared to 2017 .

Conclusion: The antibiotics dispensing law is favorably perceived among community pharmacists in Saudi Arabia despite some concerns about its impact on their sales. Exploring different business models that delink the profits from the volume of antibiotics sales is necessary for this vital industry to thrive.

Keywords: antibiotics, drug resistance, community pharmacy, sales, Saudi Arabia

\section{Introduction}

The advent of antibiotics has revolutionized medicine and made it possible to cure many bacterial infections that were deemed invincible. ${ }^{1,2}$ However, the rate of antimicrobial resistance both locally and globally has seen a dramatic increase over the past two decades. ${ }^{3-8}$ According to the World Health Organization (WHO) latest estimate, the annual worldwide death toll due to antimicrobial resistance can be as high as $50,000 .{ }^{9}$ Unfortunately, many countries and healthcare organizations are not doing enough to stem the spread of antimicrobial resistance as the global consumption of antibiotics increased by over $60 \%$ between the years of
Correspondence: Yazed AIRuthia

Tel +996| | 4677483

Fax +966114677480

Email yazeed@ksu.edu.sa
Risk Management and Healthcare Policy 2020:13 2899-2907

bmit your manuscrip

DovePress f $y$ in $>$ 
2000 and $2015 .^{10}$ The inappropriate use of antibiotics is believed to be the leading cause of antimicrobial resistance. ${ }^{11}$ Therefore, dispensing antibiotics without prescription (DAwP) in community pharmacy settings has contributed to the spread of antimicrobial resistance. ${ }^{12-14}$ In addition, the public misconceptions of antibiotics led to its misuse and contributed to the increase in the rate of DAwP. ${ }^{15}$ This was obvious in multiple studies. ${ }^{16-20}$ In a cross-sectional study that was conducted in two large hospitals in Saudi Arabia and aimed to explore the patients' awareness of antimicrobial resistance, only $27 \%$ of the patients surveyed were aware of the antimicrobial resistance. Moreover, $40 \%$ did not think that the use of antibiotics without a prescription is harmful when obtained from a friend or family member, and 34\% were unaware if this is a correct practice or not. ${ }^{16}$ Additionally, the prevalence of self-medication using antibiotics without a prescription was as high as $74 \%$ according to another study that surveyed the Sudanese population in three cities in Sudan, and community pharmacies were found to be the main source that surveyed participants get antibiotics from. ${ }^{17}$ Similarly, another study that explored the rate of DAwP in community pharmacy settings in Egypt using a simulated patient method for two viral infections scenarios (eg, acute bronchitis and common cold) found that antibiotics were dispensed in $98 \%$ of 238 visits that were made. $^{18}$ Most of the dispensed antibiotics without a prescription were taken for non-bacterial infections, such as sore throat, based on the findings of several studies. ${ }^{19,20}$ Thus, improving the public awareness regarding antibiotics is crucial to stem the spread of antimicrobial resistance.

Unfortunately, patients mostly have unlimited access to antibiotics in many countries and particularly in the Middle East. ${ }^{17-21}$ In a study that used a simulated-client method to explore the rate of DAwP in community pharmacy settings in the city of Riyadh in Saudi Arabia, antibiotics were dispensed in more than $77 \%$ of the visited pharmacies. $^{21}$ In contrast, only $7 \%$ of the dispensed antibiotics in the European Union were DAwP. ${ }^{22}$ Therefore, some countries have started taking actions against such practices that significantly contribute to the rising rate of antimicrobial resistance and put the lives of many at risk. $^{23,24}$ In Saudi Arabia, DAwP is illegal but the rate of antibiotics dispensing without a prescription has seen a dramatic increase over the last decade throughout Saudi Arabia. ${ }^{21,25,26}$ Therefore, the Saudi Ministry of Health has introduced new amendments to the existing law and included fines up to $\$ 26,666$ against the pharmacy that dispensed any antibiotic without a prescription, license revocation, pharmacy closure, and a six-month jail term. The revised antibiotics dispensing law came into effect as of May 2018. ${ }^{27}$ These amendments were introduced and enforced largely due to the failure of the previous measures that were taken by the Ministry of Health to stem the rise of antibiotics dispensing without prescription, and the increasing rate of antimicrobial resistance in the Saudi society. ${ }^{16,21}$

The community pharmacists' views of DAwP are influenced by a multitude of factors, such as their sociodemographic characteristics, professional experience, and their perception of patients who are requesting antibiotics without a prescription. ${ }^{28}$ Furthermore, patients are rarely asked to see their doctors if they requested antibiotics without a prescription according to a study that used simulated clients to explore the community pharmacy staff response to an antibiotic request without a prescription in Sri Lanka. ${ }^{29}$ Another study that explored community pharmacists' awareness of the illegality of DAwP in Saudi Arabia prior to the enforcement of the law as well as the factors that are associated with it found that more than two-thirds of the surveyed pharmacists were unaware that DAwP is illegal. Moreover, they reported that the main reasons behind the public's requests for antibiotics without a prescription were the lack of willingness to consult a physician for non-serious infections, and the inability to pay for a physician visit. ${ }^{30}$ In a qualitative study that explored the reasons behind the rise of antibiotics selfmedication among members of the general public who had an experience with antibiotics self-medication prior to the enforcement of the antibiotics dispensing law in Saudi Arabia, the difficulty in accessing healthcare services as well as poor knowledge of antibiotics resistance were found to be the main reasons. ${ }^{31}$ In addition, community pharmacists were found to play a significant role in antibiotics acquisition without a prescription by recommending certain antibiotics to pharmacy customers seeking an antibiotic without a prescription as reported in one of the studies that explored the prevalence and reasons for antibiotics self-medication among a sample of surveyed general public in Riyadh, Saudi Arabia. ${ }^{32}$ This sentiment was echoed by another cohort from the general public who were qualitatively interviewed in another study that was conducted in the eastern region of Saudi Arabia. ${ }^{33}$ However, little is known about the pharmacists' views of the DAwP after the enforcement of the executive 
regulations of the health practice law, which is colloquially known as the antibiotics dispensing law. In a recently published study that utilized an online platform to explore the impact of the antibiotics dispensing law on the public's use of antibiotics without a prescription as well as their awareness of antibiotic resistance in Saudi Arabia, only $11 \%$ of the participants reported using an antibiotic without a prescription prior to the enforcement of the law; however, this percentage has decreased to $9 \%$ after the enforcement of the law. Almost one-third of the participants were unaware of antibiotic resistance, and $84 \%$ had either a neutral or a positive attitude toward the enforced antibiotic dispensing law. ${ }^{34}$ Alrasheedy et al explored the prevalence of DAwP among community pharmacists in Al-Qassim region in Saudi Arabia using a selfadministered questionnaire and a simulated client method (SCM) for two commonly encountered infections (eg, pharyngitis and urinary tract infection) to compare the rate of DAwP before and after the law enforcement. More than two-thirds of the surveyed pharmacists reported that DWaP was common prior to the enforcement of the law; however, only $12.9 \%$ of them reported that DAwP is common after the enforcement of the law. With regard to the rate of DAwP that was measured using the SCM, $12.1 \%$ and $5.2 \%$ of the surveyed pharmacists dispensed antibiotics without prescriptions after the enforcement of the law in comparison to $96.6 \%$ and $87.7 \%$ prior to the enforcement of the law for pharyngitis and urinary tract infection, respectively. ${ }^{35}$ Although these studies have explored the prevalence and attitudes of the general public and community pharmacists about DAwP and antibiotic resistance before and after the antibiotic dispensing law enforcement, none of these studies used a probability sampling technique or explored the prevalence of DAwP in Riyadh, the capital of Saudi Arabia. In addition, the impact of the enforced antibiotics dispensing law on antibiotics sales from the community pharmacists' perspectives has not been explored. Furthermore, the total sales of oral antibiotics in Saudi Arabia has not been compared before and after the enforcement of the antibiotics dispensing law. Therefore, the aims of this study were to explore community pharmacists' views of the DAwP after the enforcement of the antibiotics dispensing law, explore its impact on antibiotics sales from their perspective, and compare the national total sales of oral antibiotics before and after the enforcement of the law. This should help inform the health policy makers in Saudi Arabia and the world about the potential unintended consequences of any law or regulation aimed at controlling the rate of antibiotic resistance.

\section{Methods}

\section{Study Design and Setting}

This was a questionnaire-based descriptive cross-sectional study that was conducted in the city of Riyadh, Saudi Arabia. Pharmacists with at least one year of work experience who had been practicing in community pharmacy settings prior to the enforcement of the antibiotics dispensing law in May 2018 have been included in the study. A multistage sampling method was used to recruit community pharmacists in the city of Riyadh. Thus, the city was divided into five main areas (North, South, East, West, and Central areas) based on the Ministry of Municipal and Rural Affairs map. These five areas were further divided into 15 main administrative districts, and each district has several neighborhoods. There are about 169 neighborhoods in Riyadh; however, many of these neighborhoods are still sparsely populated. Therefore, we included 105 neighborhoods with a population density of 50 people per square kilometer $\left(\mathrm{km}^{2}\right)$ or more based on the 2018 Saudi census for the city of Riyadh published by the Saudi General Authority of Statistics. A list of all community pharmacies in all of the 105 neighborhoods was created by locating community pharmacies using Google ${ }^{\circledR}$ map. Stratified random sampling was then conducted to select three pharmacies from each neighborhood using Microsoft Excel ${ }^{\circledR}$.

\section{Questionnaire Development}

In order to explore community pharmacists' views of the DAwP and the enforced antibiotics dispensing law, a 14item questionnaire was developed. The first six items collected data about the participants' characteristics, such as age, gender, nationality (eg, Saudi and non-Saudi), years of experience in community pharmacy settings in Saudi Arabia, type of community pharmacy (eg, independent, small-chain with less than 10 pharmacies, large chain with more than 10 pharmacies). Seven statements that inquired about community pharmacists' views of the enforced antibiotics dispensing law were created based on a previously published study, ${ }^{30}$ and the potential impact of the law on the sales of antibiotics in community pharmacies that was not investigated before. These statements were created based on identified themes that were uncovered in previously published qualitative studies that utilized the theory of planned behavior to identify the reasons behind DAwP among community pharmacists. ${ }^{36,37}$ Moreover, another 
item inquired about the most commonly dispensed class of oral antibiotics (eg, penicillins, cephalosporins, fluoroquinolones, macrolides, and tetracyclines) in the community pharmacy settings. The statements were reviewed by a medical consultant in family medicine and an expert in health policy and outcomes to check the content validity. In addition, the statements were pilot-tested among 15 pharmacists to check the face validity prior to the start of data collection. The internal consistency of the questionnaire was examined using the Cronbach's alpha method and was found to be acceptable (ie, Cronbach's alpha=0.67). ${ }^{38}$ The questionnaire was developed and administered in English.

\section{Data Collection}

Participants were asked to sign a written consent form that explained the purpose of the study and their right to withdraw from the study at any time. Only those who signed the consent form were included in the study. Five trained medical interns visited the randomly selected pharmacies and interviewed the community pharmacists who consented to participate. The medical interns were provided training through a role play, and they were asked to adhere to a written protocol on how to approach the potential participants, obtain the consent form, and conduct the interview. In case more than one pharmacist was present in a pharmacy, the medical interns were instructed to interview them separately after obtaining their written consent forms. In order to examine any potential impact of the enforced antibiotics dispensing law on the sales of oral antibiotics at the national level, the national sales data of orally administered antibiotics were retrieved from the Saudi Food and Drug Authority (SFDA) database for the years of 2017, 2018, and 2019. This dataset includes the consumption rates and sales of all approved medications by the SFDA. Licensed pharmaceutical importers, local manufacturers, and multinational pharmaceutical companies' representatives in Saudi Arabia are required to provide information on their sales of all registered medications to the SFDA. A query was made to retrieve data on orally administered antibiotics given their high utilization rates in the community.

\section{Statistical Analysis}

The minimum sample size was estimated to be 260 participants for chi-square test based on a $\beta / \alpha$ ratio of 1 , medium effect size (Cohen's $w=0.2$ ), and power of 0.85 (1- $\beta$ error probability). Descriptive statistics using frequencies and percentages were used to present the findings of the study. Pearson's correlation coefficient $(r)$ was used to examine the association between the views of the community pharmacists and their characteristics (eg, years of experience, age, gender, education, etc.). All statistical analyses were conducted using SAS $^{\circledR}$ version 9.4 (SAS institute, Cary, NC, U.S). The study was approved by the institutional review board of the College of Medicine at King Saud University, Riyadh, Saudi Arabia (Research Project No. E-19-4421).

\section{Results}

\section{Participants' Characteristics}

There were 355 pharmacists in over 300 pharmacies who were approached and asked if they would like to participate. However, 33 pharmacists did not consent to participate, and 36 pharmacists did not meet the inclusion criteria (eg, fresh graduates); 286 pharmacists met the inclusion criteria and were included in the analysis. Most of the participants were between 30 to 40 years of age (57.34\%), and about one-third $(34.97 \%)$ were under 30 years of age. The majority of the participants were male (97.90\%), and non-Saudi (95.10\%). About three-quarters of the participants work in large-chain pharmacies, and only $8.39 \%$ of them work in independent pharmacies. Most of the participants have a bachelor of pharmacy degree $(97.20 \%$ ), and only $2.80 \%$ of them reported having a post-graduate degree (eg, post-graduate diploma or Master of Science). Almost 54\% of the participants had 1 to 5 years of experience in community pharmacy settings in Saudi Arabia, and about $32 \%$ had 5 to 10 years of experience (Table 1).

\section{Pharmacists' Views of the DAwP After the Enforcement of the Antibiotics Dispensing Law}

After the enforcement of the law, approximately $51.40 \%$ of the participants reported that the percentage of patients who ask for antibiotics without a prescription does not exceed $25 \%$ of the total number of patients who visit community pharmacies, while $34.62 \%$ reported that the percentage can be as high as $50 \%$. Moreover, the majority $(87.41 \%)$ reported a decrease in the sales of antibiotics. The inappropriate use of antibiotics is believed to be reduced by $89.51 \%$ based on the participants' responses. However, approximately $10 \%$ of the participants disagree that the inappropriate use of antibiotics will decrease as a result of the enforcement of the antibiotics dispensing law. Likewise, the majority of participants $(90.56 \%)$ agreed that the law enforcement will reduce the rate of antimicrobial resistance, but $9.44 \%$ disagreed. Most of the participants (64.69\%) disagreed that DAwP is still common after the enforcement of 
Table I Characteristics of the Participants $(N=286)$

\begin{tabular}{|c|c|}
\hline Characteristics & $N(\%)$ \\
\hline \multicolumn{2}{|l|}{ Age in years (yrs) } \\
\hline$<30$ yrs & $100(34.97)$ \\
\hline $30-40$ yrs & $164(57.34)$ \\
\hline$>40 \mathrm{yrs}$ & $22(7.69)$ \\
\hline \multicolumn{2}{|l|}{ Gender } \\
\hline Male & $280(97.90)$ \\
\hline Female & $6(2.10)$ \\
\hline \multicolumn{2}{|l|}{$\begin{array}{l}\text { Years of experience in community pharmacy } \\
\text { settings in Saudi Arabia }\end{array}$} \\
\hline $1-5$ yrs & $154(53.85)$ \\
\hline $5-10 \mathrm{yrs}$ & $91(31.82)$ \\
\hline$>10 \mathrm{yrs}$ & $4 \mid(14.34)$ \\
\hline \multicolumn{2}{|l|}{ Type of pharmacy } \\
\hline Independent & $24(8.39)$ \\
\hline Small-chain & $47(16.43)$ \\
\hline Large-chain & $215(75.17)$ \\
\hline \multicolumn{2}{|l|}{ Education } \\
\hline Bachelor of Pharmacy & $278(97.20)$ \\
\hline Post-graduate degree (eg, Master of Science) & $8(2.80)$ \\
\hline \multicolumn{2}{|l|}{ Nationality } \\
\hline Saudi & $14(4.90)$ \\
\hline Non-Saudi & $272(95.10)$ \\
\hline
\end{tabular}

the law; however, about $35 \%$ of them either agreed that DAwP is still common or were not sure. The majority of participants (97.90\%) agreed that pharmacists must ask patients to consult their physicians to check if they need antibiotics. Pharmacy profits are believed to be negatively impacted by the law enforcement according to $41.26 \%$ of the participants; however, $52.80 \%$ of them did not agree that their pharmacies' sales were negatively impacted by the law (Table 2). With the exception of the years of experience in community pharmacy settings in Saudi Arabia, which has shown a negative correlation with the percentage of patients requesting antibiotics without a prescription $(r=-0.152, P=0.009)$, none of the participants' views were influenced by their sociodemographic characteristics.

\section{Most Commonly Dispensed Oral Antibiotics and the Law Enforcement Impact on Total Sales of Orally Administered Antibiotics}

The majority of the participants $(62.6 \%)$ reported that penicillins (eg, amoxicillin) and cephalosporins (eg, cephalexin, cefadroxil, cefaclor, cefuroxime, and cefixime) are the most commonly dispensed oral antibiotics in their pharmacies as shown in Figure 1. According to the SFDA database the total sales of oral antibiotics have seen a decrease from $\$ 480$ million in 2017 prior to the enforcement of the antibiotics dispensing law to $\$ 420$ million in 2018 where the law was enforced in the month of May of the same year, and to $\$ 400$ million in 2019 (Figure 2).

\section{Discussion}

Most of the surveyed community pharmacists in this study viewed the enforced antibiotics dispensing law favorably with regard to reducing the rate of DAwP as well as the antibiotic resistance. However, a significant minority (eg, $41.26 \%$ ) believed that the law enforcement has negatively affected their pharmacies' profits. These findings are important in informing health policy makers about the impact that such a law could have not only on the incidence rate of antibiotic resistance and misuse but also on the unintended economic consequences of such laws and regulations. This is particularly important in Saudi Arabia which has seen a dramatic increase in the rate of antimicrobial resistance and high rate of DAwP over the last two decades. ${ }^{3-8}$ The high rate of DAwP in community pharmacy settings was attributable to weak implementation of regulations, poor understanding of the local regulations and laws that prohibit such practice, and the desire to maximize profits in the absence of any legal deterrence. ${ }^{25,30,39}$ However, only $25 \%$ of the surveyed community pharmacists in this study reported that DAwP is still a common issue. In addition, about $98 \%$ agreed that they should ask the patients to consult their physicians to check if they really need an antibiotic. Moreover, the majority of surveyed community pharmacists $(>85 \%)$ agreed that the law enforcement will reduce the rates of inappropriate use and resistance to antibiotics. These findings are close to the findings of another study that was conducted in the region of Al-Qassim in Saudi Arabia and found a positive impact of the law enforcement on community pharmacists' knowledge and views of DAwP. ${ }^{35}$.

The majority of surveyed community pharmacists have reported a decrease in the sales of antibiotics after the enforcement of the law, which is consistent with the previously published studies. ${ }^{35,39}$ Moreover, a significant percentage of participants $(41.2 \%)$ reported that the law enforcement has negatively impacted their profits, which is close to the percentage reported in the recently published study. ${ }^{35}$ This indicates that sales of antibiotics represent a significant 
Table 2 Community Pharmacists' Agreement with Different Statements Regarding the New Antibiotics Dispensing Law and Dispensing Antibiotics without Prescription

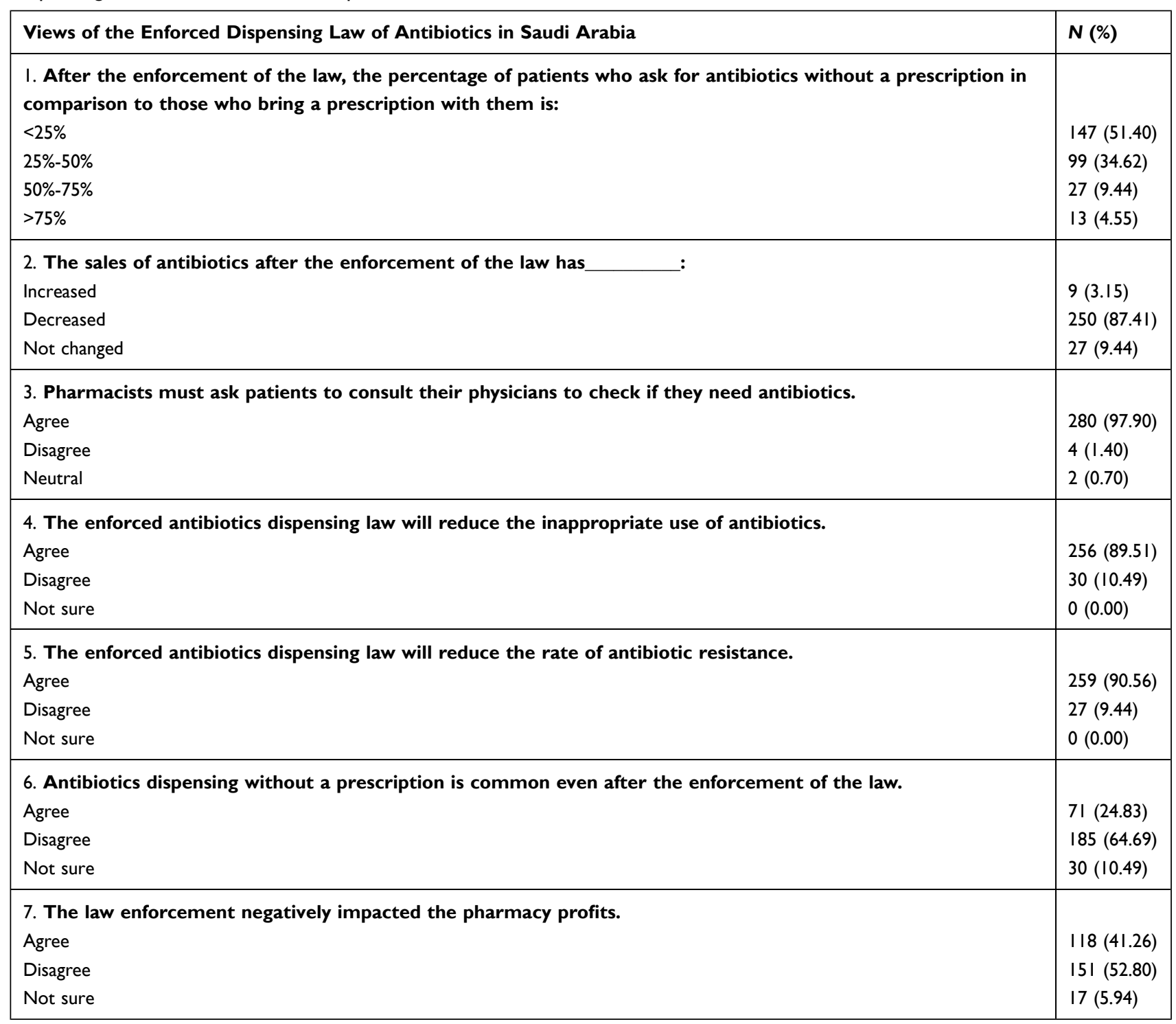

proportion of community pharmacies' profits in Saudi Arabia. Therefore, community pharmacies need to diversify their revenues by adopting and implementing value-added services, such as anticoagulation services, osteoporosis screenings, travel health, lipid screenings, and smoking cessation counseling. ${ }^{40}$ The participants' length of work experience in community pharmacy settings in Saudi Arabia was associated with lower estimates of pharmacy customers who request antibiotics without a prescription. This can be attributable to the better ability of community pharmacists with long work experience to estimate the percentage of patients who requested antibiotics without a prescription in comparison to their counterparts with short work experience. Moreover, customer pressure may play a role as suggested by one of the studies that explored the factors associated with dispensing sub-therapeutic doses of antibiotics without prescriptions. ${ }^{41}$ Pharmacy customers may feel that it is easier to pressure young pharmacists with short experience to dispense antibiotics without a prescription in comparison to older pharmacists who look more experienced.

Beta-lactam antibiotics (eg, penicillins and cephalosporins) were the most commonly dispensed antibiotics in community pharmacies based on the surveyed participants. This is consistent with the previously published research studies that reported high dispensing rates of beta-lactam antibiotics prior to the law enforcement, which contributed to the increasing incidence rates of BLPB. ${ }^{3,4}$ The national sales of oral antibiotics have seen a decline after the enforcement of 


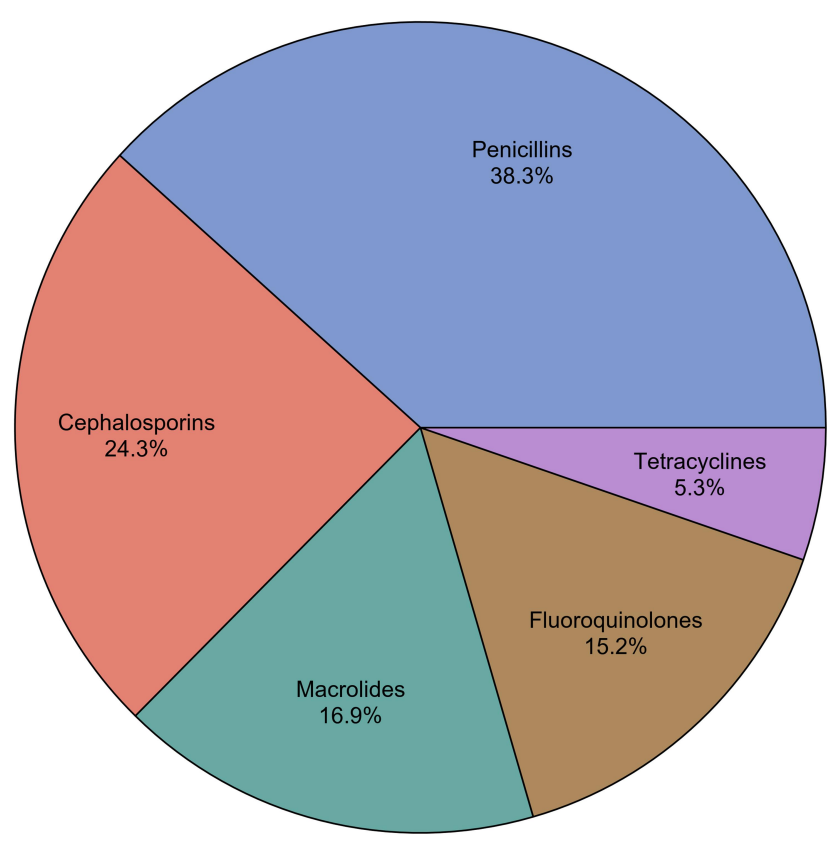

Figure I The most commonly dispensed oral antibiotics in community pharmacy settings based on the participants' responses.

the law in 2019 in comparison to the sales data of 2017 when the law was not enforced. This highlights a potential role of the law enforcement in decreasing the sales of oral antibiotics which were commonly dispensed without a prescription in community pharmacies prior to the enforcement of the law. The high inappropriate use of antibiotics is one of the main contributors to the increasing rate of antimicrobial resistance. ${ }^{30,35}$ However, the antibiotics manufacturers have an incentive to increase their sales of antibiotics in order to generate more profits. Therefore, the sustainability of this business model in light of different antimicrobial stewardship programs and the law enforcement is at stake. $^{42}$ The United Kingdom has recently adopted a subscription style model for antibiotics to encourage pharmaceutical companies to invest in developing new antibiotics and secure payment for antibiotics manufacturers upfront based on the value that their antibiotics provide rather than the utilized quantities. ${ }^{43}$ This kind of model that delinks the profits from the volume of sales for antibiotics and encourages pharmaceutical manufacturers to invest in the research and development of antibiotics is needed. ${ }^{43}$

Although this study is the first, to the best of our knowledge, to explore community pharmacists' views of the enforced antibiotics dispensing law in Riyadh and the second in the Saudi Arabia, the study is not without limitations. First, this study was only conducted in one city which limits the generalizability of the findings. Moreover, interviewer bias cannot be ruled out since the questionnaire was administered by interviewing participants rather than being self-administered by the participants themselves. In addition, the rate of DAwP from the perspective of community pharmacists was not explored.

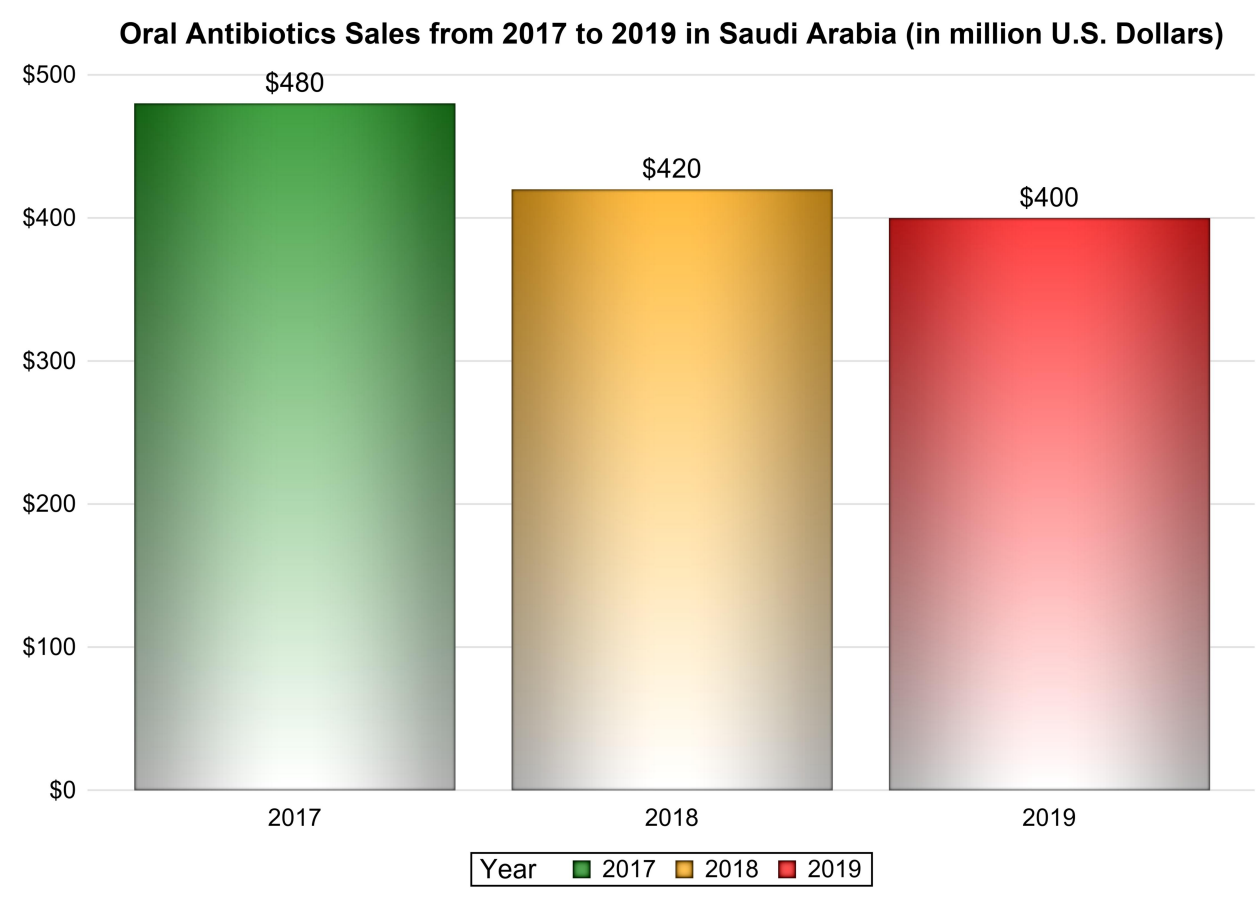

Figure 2 The sales of oral antibiotics in Saudi Arabia between 2017 and 2019 based on the SFDA database. 


\section{Conclusions}

The findings of this study suggest that community pharmacists have generally favorable views of the enforced antibiotics dispensing law in Saudi Arabia. Moreover, the enforcement of the law is potentially behind the drop of oral antibiotics sales. Future studies should explore the impact of the law enforcement on the rate of antibiotic resistance in Saudi Arabia. In addition, different payment models for antibiotics based on their therapeutic value rather than the volume of sales should be explored to incentivize local manufacturing of antibiotics and encourage research and development in this vital therapeutic area.

\section{Abbreviations}

DAwP, dispensing antibiotics without prescription; WHO, World Health Organization; SFDA, Saudi Food and Drug Authority; BLPB, beta-lactamase-producing bacteria.

\section{Data Sharing Statement}

Study data are de-identified and can be available upon request from the corresponding author (Yazed AlRuthia).

\section{Acknowledgments}

The authors acknowledge financial support from Researchers Supporting Project number (RSP-2020/16), King Saud University, Riyadh, Saudi Arabia.

\section{Disclosure}

The authors report no conflicts of interest in this work.

\section{References}

1. Goldsworthy PD, McFarlane AC. Howard Florey, Alexander Fleming and the fairy tale of Penicillin. Med J Australia. 2002;176(4):178. doi:10.5694/j.1326-5377.2002.tb04349.x

2. Aminov RI. A brief history of the antibiotic era: lessons learned and challenges for the future. Frontiers in Microbiology. 2010;1:134. doi: $10.3389 /$ fmicb. 2010.00134

3. Aly M, Balkhy HH. The prevalence of antimicrobial resistance in clinical isolates from Gulf Corporation Council countries. Antimicrob Resist Infect Control. 2012;1(1):26.

4. Mazrou YY, Khoja TA, Aziz KM, Salem AM. High proportion of multi-drug resistant Mycobacterium tuberculosis in Saudi Arabia. Scand J Infect Dis. 1997;29:p. 323.

5. Al-Tawfiq JA. Increasing Antibiotic Resistance Among Isolates of Escherichia coli Recovered From Inpatients and Outpatients in a Saudi Arabian Hospital. Infect Control Hosp Epidemiol. 2006;27 (7):748-753.

6. Bilal NE, Gedebou M. Clinical and community strains of Klebsiella pneumoniae: multiple and increasing rates of antibiotic resistance in Abha, Saudi Arabia. Br J Biomed Sci. 2000;57(3):185-191.

7. World Health Organization. Antimicrobial resistance: global report on surveillance 2014. World Heal Organ [Internet]. 2014;1-257. Available from: http://www.who.int/drugresistance/documents/surveil lancereport/en/. Accessed November 21, 2020.
8. Klein EY, Van Boeckel TP, Martinez EM, et al. Global increase and geographic convergence in antibiotic consumption between 2000 and 2015. Proc Natl Acad Sci U S A. 2018;115(15):E3463-70. doi:10.1073/pnas.1717295115

9. Goossens H, Ferech M, Vander Stichele R, Elseviers M. Outpatient antibiotic use in Europe and association with resistance: A cross-national database study. Lancet. 2005;365(9459):579-587. doi:10.1016/S0140-6736(05)70799-6

10. Lipsitch M, Samore MH. Antimicrobial use and antimicrobial resistance: a population perspective. Emerg Infect Dis. 2002;8 (4):347-354. doi:10.3201/eid0804.010312

11. Nga DTT, Chuc NTK, Hoa NP, et al. Antibiotic sales in rural and urban pharmacies in northern Vietnam: an observational study. $B M C$ Pharmacology and Toxicology. 2014;15(1):6. doi:10.1186/20506511-15-6

12. Kwena Z, Sharma A, Wamae N, Muga C, Bukusi E. Provider characteristics among staff providing care to sexually transmitted infection self-medicating patients in retail pharmacies in Kibera slum, Nairobi, Kenya. Sex Transm Dis. 2008;35(5):480-483. doi:10.1097/ OLQ.0b013e3181644b84

13. Ventola CL. [Review] The antibiotic resistance crisis: part 1: causes and threats. Pharm Ther. 2015;40:4.

14. Yagoub U, Al Qahtani B, Al HI, Al Zahrani A, Siddique K. $<\mathrm{p}>$ Antibiotic resistance: a hospital-based multicenter study in Tabuk city, Kingdom of Saudi Arabia. <![CDATA[Infection and Drug Resistance]]>. 2019;12:1815-1825. doi:10.2147/IDR.S200996

15. Awad A, Eltayeb I, Matowe L, Thalib L. Self-medication with antibiotics and antimalarials in the community of Khartoum State, Sudan. $J$ Pharm Pharm Sci. 2005;8(2):326-331.

16. Abdelaziz AI, Tawfik AG, Rabie KA, et al. Quality of Community Pharmacy Practice in Antibiotic Self-Medication Encounters: A Simulated Patient Study in Upper Egypt. Antibiotics. 2002;20 (4):253-257.

17. Borg MA, Scicluna EA. Over-the-counter acquisition of antibiotics in the Maltese general population. Int J Antimicrob Agents. 2002;20 (4):253-7.

18. Togoobaatar G, Ikeda N, Ali M, et al. A survey of non-prescribed use of antibiotics for children in an urban community in Mongolia. Bull World Health Organ. 2010;88(12):930-936. doi:10.2471/BLT.10.079004

19. Bin Abdulhak AA, Altannir MA, Almansor MA, et al. Non prescribed sale of antibiotics in Riyadh, Saudi Arabia: a cross sectional study. $B M C$ Public Health. 2011;11(1):538. doi:10.1186/1471-2458-11-538

20. AMR. $7 \%$ of antibiotics in the EU are taken without a prescription | antimicrobial Resistance [Internet]; 2020. Available from: https://ec. europa.eu/health/amr/news/amr-7-antibiotics-eu-are-taken-withoutprescription_en.

21. Morgan DJ, Okeke IN, Laxminarayan R, Perencevich EN, Weisenberg S. Non-prescription antimicrobial use worldwide: a systematic review. Lancet Infect Dis. 2011;11(9):692-701. doi:10.1016/S1473-3099(11)70054-8

22. Al-Azzam SI, Al-Husein BA, Alzoubi F, Masadeh MM, Al-Horani A. Self-medication with antibiotics in Jordanian population. Int J Occup Med Environ Health. 2007;20(4):373-380. doi:10.2478/ v10001-007-0038-9

23. Al-Mohamadi A, Badr A, Bin Mahfouz L, Samargandi D, Al Ahdal A. Dispensing medications without prescription at Saudi community pharmacy: extent and perception. Saudi Pharm J SPJ off Publ Saudi Pharm Soc. 2013;21(1):13-18.

24. Al Rasheed A, Yagoub U, Alkhashan H, et al. Prevalence and Predictors of Self-Medication with Antibiotics in Al Wazarat Health Center, Riyadh City, KSA. Biomed Res Int. 2016;2016.

25. Ministry of Health. MOH Warns Against Selling Antibiotics without Prescription [Internet]. MOH News. 2018. Available from: https:// www.moh.gov.sa/en/Ministry/MediaCenter/News/Pages/news-201804-17-004.aspx. Accessed November 21, 2020. 
26. Servia-Dopazo M, Figueiras A. Determinants of antibiotic dispensing without prescription: A systematic review. $J$ Antimicrobial Chemother. 2018;73(12):3244-3253. doi:10.1093/jac/dky319

27. Zawahir S, Lekamwasam S, Aslani P. Antibiotic dispensing practice in community pharmacies: A simulated client study. Res Soc Adm Pharm. 2019;15(5):584-590. doi:10.1016/j.sapharm.2018.07.019

28. Hadi MA, Karami NA, Al-Muwalid AS, et al. Community pharmacists' knowledge, attitude, and practices towards dispensing antibiotics without prescription (DAwP): A cross-sectional survey in Makkah Province, Saudi Arabia. International Journal of Infectious Diseases. 2016;47:95-100. doi:10.1016/j.ijid.2016.06.003

29. Alhomoud F, Aljamea Z, Basalelah L. "Antibiotics kill things very quickly" - consumers' perspectives on non-prescribed antibiotic use in Saudi Arabia. BMC Public Health. 2014;15(1):1-2. doi:10.1186/ s12889-018-6088-z

30. Nafisah SB, Nafesa SB, Alamery AH, Alhumaid MA, AlMuhaidib HM, Al-Eidan FA. Over-the-counter antibiotics in Saudi Arabia, an urgent call for policy makers. J Infect Public Health. 2017;10(5):522-526. doi:10.1016/j.jiph.2016.09.016

31. Alhomoud F, Almahasnah R, Alhomoud FK. "You could lose when you misuse"-factors affecting over-the-counter sale of antibiotics in community pharmacies in Saudi Arabia: a qualitative study. BMC Health Serv Res. 2018;18(1):1-9.

32. Kurdi S, Faran A, Eareeni E, et al. Assessment of knowledge and attitude toward the new antibiotic dispensing law and its effect on antibiotic use in Saudi Arabia. Saudi Pharm J. 2020;28(1):58-67.

33. Alrasheedy AA, Alsalloum MA, Almuqbil FA, et al. The impact of law enforcement on dispensing antibiotics without prescription: a multi-methods study from Saudi Arabia. Expert Rev Anti Infect Ther. 2020;18(1):87-97.

34. Roque F, Soares S, Breitenfeld L, López-Durán A, Figueiras A, Herdeiro MT. Attitudes of community pharmacists to antibiotic dispensing and microbial resistance: a qualitative study in Portugal. Int J Clin Pharm. 2013;35(3):417-424.
35. Erku DA, Aberra SY. Non-prescribed sale of antibiotics for acute childhood diarrhea and upper respiratory tract infection in community pharmacies: a 2 phase mixed-methods study. Antimicrob Resist Infect Control. 2018;7(1):92.

36. Tavakol M, Dennick R. Making sense of Cronbach's alpha. Int j Med Educ. 2011;2:53.

37. Jacobs TG, Robertson J, van den Ham HA, Iwamoto K, Bak Pedersen H, Mantel-Teeuwisse AK. Assessing the impact of law enforcement to reduce over-the-counter (OTC) sales of antibiotics in low- and middle-income countries; a systematic literature review. BMC Health Serv Res. 2019;19(1):536.

38. Desselle SP, Moczygemba LR, Coe AB, Hess K, Zgarrick DP. Applying Contemporary Management Principles to Implementing and Evaluating Value-Added Pharmacist Services. Pharmacy. 2019;7(3):99.

39. Amin ME, Amine A, Newegy MS. Perspectives of pharmacy staff on dispensing subtherapeutic doses of antibiotics: a theory informed qualitative study. Int J Clin Pharm. 2017;39(5):1110-1118.

40. Zowawi HM, Balkhy HH, Walsh TR, Paterson DL. $\beta$-Lactamase production in key gram-negative pathogen isolates from the Arabian Peninsula. Clin Microbiol Rev. 2013;26(3):361-380. doi:10.1128/CMR.00096-12

41. Yezli S, Shibl AM, Livermore DM, Memish ZA. Antimicrobial resistance among Gram-positive pathogens in Saudi Arabia. $J$ Chemother. 2012;24.

42. Outterson K New business models for sustainable antibiotics. Centre on Global health Security Working Group Papers, Chatham House (The Royal Institute of International Affairs), Working Groups on Antimicrobial Resistance, Paper. 2014;1:10-14.

43. Mahase E. UK launches subscription style model for antibiotics to encourage new development. BMJ. 2020;369:m2468.
Risk Management and Healthcare Policy

\section{Publish your work in this journal}

Risk Management and Healthcare Policy is an international, peerreviewed, open access journal focusing on all aspects of public health, policy, and preventative measures to promote good health and improve morbidity and mortality in the population. The journal welcomes submitted papers covering original research, basic science, clinical \& epidemiological studies, reviews and evaluations, guidelines, expert opinion and commentary, case reports and extended reports. The manuscript management system is completely online and includes a very quick and fair peer-review system, which is all easy to use. Visit http://www.dovepress.com/testimonials.php to read real quotes from published authors. 